\title{
Tools for evaluating the sustainability of urban design: a review
}

Jorge Gil MSc

PhD Researcher, Department of Urbanism, Faculty of Architecture, Delft University of Technology, Delft, the Netherlands
José Pinto Duarte MSc, PhD

Full Professor, Faculty of Architecture, Technical University of Lisbon, Lisbon, Portugal

The present policy objective of sustainable urban development has created the need for methods of ex ante evaluation of local area development projects that assess the contribution of alternative solutions to the general sustainability goals. For this reason, we have seen the evolution of building energy assessment methods into sustainable neighbourhood assessment methods that are more integrative and contextual to accommodate the complexities of the urban scale. This article identifies and reviews a selection of sustainable urban development evaluation tools that are applicable to the early stages of urban design projects, to provide a clearer picture of the state of play to those needing to use such tools and those wanting to develop new ones. The review follows an analytical framework covering the format, structure, content and output of the tools, based on the recommendations of planning evaluation theory and the requirements of urban design practice. Since no single tool stands out from the review, the choice is not simple and there is scope both to further improve existing tools and develop new ones. The paper concludes proposing a strategy for the development of robust and compatible sustainable urban development evaluation methods based on four goals: collaboration, compatibility, customisation and combination.

\section{Introduction}

The report 'Sustainable Urban Development in the European Union: A Framework for Action' (European Commission, 1998) and the Leipzig Charter (European Council, 2007) have laid out the principles and strategies towards a sustainable urban development policy to be followed by national and local governments. Furthermore, several national policy and guidance documents (e.g. the Fifth National Policy Document on Spatial Planning in the Netherlands (VROM, 2001), Planning Policy Statement 1 in the UK (DCLG, 2005) and the Sustainable Urban Development Act of 2010 in the USA (USC, 2010)) have put sustainable development as the core objective of planning. However, evaluation procedures are necessary to assess if local urban development initiatives can contribute to progress towards the national goals of sustainable urban development (Curwell and Cooper, 1998; Hunt et al., 2008; Oliveira and Pinho, 2010). Academia, industry and government have thus developed several evaluation methods and frameworks to support decision making during the sustainable urban development process (Bentivegna et al., 2002; Brandon and Lombardi, 2010). Due to the complexity of planning's process and objective, there is not a unique evaluation approach: the evaluation methods and frameworks that exist are appropriate for specific stages of the urban development process, for specific spatial or temporal scales of development, and often for specific sustainability issues.
This review addresses current sustainable urban development evaluation tools that are holistic in the coverage of sustainable development issues, can support the assessment of alternative urban design options at the neighbourhood scale and are applicable from the early stages of the design phase of the urban design process (Llewelyn-Davies and Alan Baxter \& Associates, 2007: p. 110; RIBA, 2007). The aim is to assess not only the compliance of these sustainable urban development evaluation tools with the recommendations of planning theory but also their adequacy for use in urban design practice in order to facilitate the choice of tool or to guide the future development of new tools. Here, the term 'tool' is used in a broad sense, encompassing a range of design and decision support instruments.

The next section of this paper reviews the methods of sustainability evaluation from planning theory in light of the requirements of evaluation tools for planning practice, compiling a set of key principles from both domains. This lays out the foundations for the analytical framework presented in Section 3, which addresses the format, structure, content and output of sustainable urban development evaluation tools. Section 4 describes the process of identification and selection of relevant sustainable urban development evaluation tools, resulting in a summary of the tools reviewed. This is followed by an analysis 
Urban Design and Planning

Volume 166 Issue DP6
Tools for evaluating the

sustainability of urban design:

a review

Gil and Duarte of the tools, based on the analytical framework presented earlier in the paper, highlighting the general trends and particular characteristics of individual tools. The paper concludes with a discussion of the development of sustainable urban development evaluation tools and how this should be used to link planning evaluation theory and urban design practice.

\section{The evaluation of sustainable urban design}

There has been a constant evolution of planning evaluation methods, from cost benefit analysis (CBA) to planning balance sheet (PBS) and multi-criteria analysis (MCA), from environmental impact assessment (EIA) to strategic environmental assessment (SEA) and social impact assessment (SIA). According to Alexander (2006), this evolution has represented recognition of the complexities of the evaluation process in urban planning and has resulted in a move to scientifically and technically more sophisticated methods: from 'simple' calculation methods to complex assessment frameworks; from an environmental focus to an integrated sustainability agenda; from an aggregated or reductionist strategy to a disaggregated and multi-dimensional approach. This evolution reflects the progress of planning evaluation theory from a positivist stance of instrumental rationality to a dialectic stance of communicative rationality (Khakee, 2003).

On the other hand, planning practice has remained positivist, believing in objective quantitative measurement (Khakee, 2003). This is reflected in the adoption of indicator systems and aggregate indices for the monitoring of sustainable urban development progress, such as the European common indicators (ECI) (AIRI, 2003) or the UK sustainable development indicators pocket guide (Defra, 2009). The adoption of simpler evaluation methods is linked to the requirements of planning practice and policy (Briassoulis, 2001; Rydin et al., 2003), since practice needs normative and positive theory (Alexander, 1997 2000). Therefore, despite the mandate for EIA in the USA and for SEA or EIA in the European Union (EU), these complex frameworks have limited use in practice (Hacking and Guthrie, 2008; Jensen and Elle, 2007; Steinemann, 2001). Their complexity of implementation and information gathering demands reduce their ability to function in a quick, iterative and interactive fashion, which is a requirement of smaller projects and in the early stages of any project (Becker, 2004; Cole, 1999; Ding, 2008). Disaggregate indicator systems, combined with MCA principles, have become the preferred method of evaluation at a more local and detailed scale of planning, such as neighbourhood development and design (Carmona, 2003; Colantonio, 2008; Hacking and Guthrie, 2008).

This field has also witnessed an evolution since the late 1990s. The building energy measurement and rating systems used in the building design process (e.g. GBTool, Leed, Breeam) started to embrace a more holistic perspective towards sustainability and the measurement of performance against benchmarks (Cooper, 1999). With this step it also became clear that the evaluation of sustainable urban development of an urban area could not be restricted to the measurement of the individual buildings that constitute it, due to the systemic nature of the urban environment (Curwell and Cooper, 1998). This was recently demonstrated by the post-occupancy assessment of the flagship zero carbon development BedZED, in the UK, where location and accessibility were the most often cited problems by residents (BioRegional, 2009). New sustainable urban development evaluation frameworks were created that kept the simpler quantitative nature of the original indicator systems, but would address the context of urban design, the social and public dimensions of the problem, and the characteristics of the planning process (Curwell and Cooper, 1998). The sustainable urban development evaluation frameworks need to respond to several requirements in order to be effectively applied as decision and design support tools to urban design practice in the ex ante evaluation of design proposals. They need to

have an integrated conception of sustainable urban development (Gasparatos et al., 2009; Hacking and Guthrie, 2008; Munda, 2006)

reflect a widely accepted vision that provides guidance during the design process (Cole, 1999, 2005; Jensen and Elle, 2007; Leitmann, 1999)

agree objectives and targets to work towards, instead of comparing to the reference baseline scenario (Cole, 1999; Pope et al., 2004)

allow for early stage deployment, when few data on a project are available (Cole, 1999; Hunt et al., 2008)

- use disaggregate measures and include MCA features (Ding, 2008; Gasparatos et al., 2009; Hacking and Guthrie, 2008; Munda, 2006)

offer interaction with the design and be sensitive to design changes (Cole, 1999; Leitmann, 1999)

allow for (re)iteration, assessing alternatives and supporting the evolution of the design (Becker, 2004; Cole, 1999, 2005; Leitmann, 1999; Oliveira and Pinho, 2010)

offer communication methods that make the results clear and understandable to the various stakeholders (Becker, 2004; Cole, 1999; Leitmann, 1999; Oliveira and Pinho, 2010; Walton et al., 2005)

assess the planning process itself in terms of dialogue and participation of the various stakeholders (Gaffron et al., 2008; Khakee, 2003; Munda, 2006; Oliveira and Pinho, 2010).

This set of requirements lays out the foundation of the analytical framework used to review selected sustainable urban development evaluation tools. 


\section{An analytical framework for sustainable urban development evaluation tools}

This section introduces the analytical framework used to assess how the selection of sustainable urban development evaluation tools responds to the needs of urban design practice and if it follows the recommendations of planning evaluation theory. This analytical framework focuses on four different aspects of the tools, namely their format, structure, content and output. The format is about their type and what they offer as product. The structure is about how the concept of sustainable urban development is implemented and organises the system of indicators. The content is about the different themes addressed by the individual indicators. Finally, the output is about the way the results are processed and presented.

\subsection{Tool format}

The selected sustainable urban development evaluation tools are classified according to one of the following tool types, adapted from Jensen and Elle's typology (2007) to fit the specificities of the design phase of the urban design process.

Design guides are descriptive collections of sustainable urban development themes that present general principles and, in some cases, a detailed structure of indicators that includes benchmark values. They often offer checklists as practical instruments to guide the design process.

- Calculation tools are software tools for the direct calculation of sustainable urban development indicators. They do not offer a fixed evaluation framework but allow the aggregation of indicators for visualisation in simple charts and, in some cases, display thematic maps of individual indicators.

- Assessment tools are advanced checklists with software implementation. Values are entered in forms for each sustainable urban development theme of a structured evaluation framework and the results are plotted in charts to give a visual and quantitative profile of different design options.

- Rating systems are similar to assessment tools, but the output is a label with a score. They require precise calculation of indicators and include target values and weights for aggregating the results into the final score.

It is also important to note the software platform that supports the tool and what method of data input is offered. Finally, one must understand the possibilities for customising the tool for the specific context of the project by configuring or selecting the indicators (Becker, 2004; Pope et al., 2004).

\subsection{General tool structure}

An essential characteristic of a sustainable urban development evaluation tool is that it should offer a hierarchical structure supporting the selection and development of meaningful sustainability indicators (Archibugi, 2006; Becker, 2004). This structure progressively links higher level concepts of sustainability, present in policy targets and the development vision, to specific issues that are relevant to the project and to objectives that can be measured (Briassoulis, 2001; Mitchell, 1996). This hierarchy should provide compatibility with evaluation standards and theory, provide a clearer understanding of the issues and give greater relevance to the results (Carmona and Sieh, 2008).

The proposed general structure for sustainable urban development evaluation tools consists of the following five hierarchical levels with increasing detail and specificity.

- Sustainability dimensions are the core goals of sustainability, often based on the three pillars, also known as triple bottom line (TBL), of environment, society and economy.

- Urban sustainability issues are the themes of concern to sustainable urban development that need to be addressed to achieve the core goals (e.g. resources, accessibility, viability).

Evaluation criteria are the aspects that need to be assessed in order to verify the response of the plan to the issue (e.g. energy consumption, waste production, access to public transport or access to jobs).

- Design indicators are measurements that are indicative of the performance of the design, with specific measurement units and methods (e.g. percentage of residents within $400 \mathrm{~m}$ walking distance of a public transit stop, average distance in meters to the nearest doctor).

Benchmark values are the reference or target values that the indicators need to meet to achieve specific quality levels: reference values come from a baseline assessment of similar cases, while target values are objective goals from a more universal sustainability vision.

Figure 1 presents the general tool structure, with the size of each level indicative of the expected number of elements. This diagram highlights the critical transitions between levels, where one has to associate general sustainability concepts with urban environment specific concepts, and translate theoretical concepts into empirical measures (Pope et al., 2004), supported by research, theories and empirical evidence. Furthermore, the arrow on the left indicates a top-down direction of definition of the system of indicators, starting from the high-level sustainability principles. Pope et al. (2004) suggest starting at the issues level because the TBL can be reductionist; however, we understand this to be a problem only if indicators are directly linked to the dimensions of sustainability, without the intermediate levels. The arrow on the right indicates the bottom-up direction of measurement and aggregation for interpretation of the evaluation results, where the indicators linked to objectives influence the path of action towards sustainability (Pope et al., 2004). 


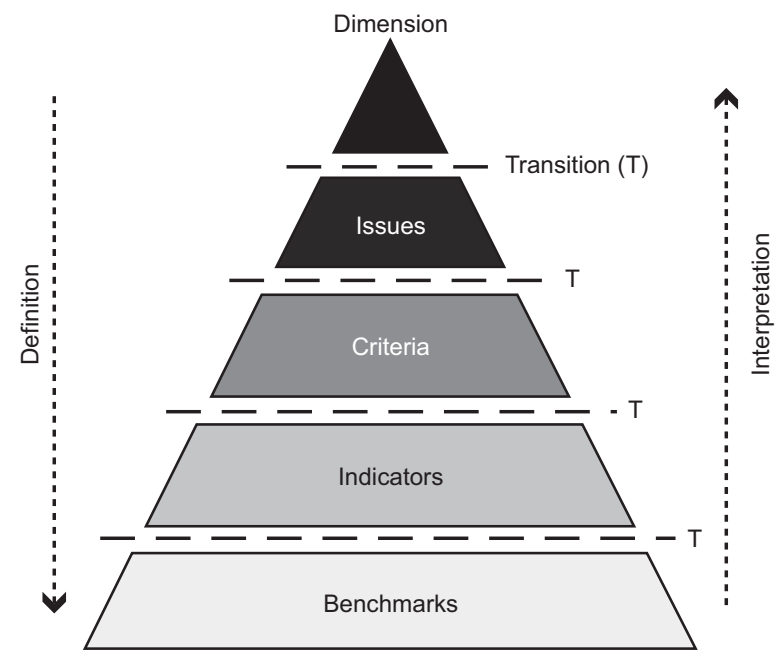

Figure 1. General structure of sustainable urban development evaluation tools with five hierarchical levels, indicating a top-down definition and a bottom-up interpretation of the system of indicators and benchmarks, with critical conceptual transitions between levels, requiring either theory or empirical evidence

\subsection{Tool content}

The content of the selected sustainable urban development evaluation tools is reviewed by identifying what each individual indicator is measuring and viewing it under two different lenses, to assess the tool's applicability to the early stages of the design phase of the urban design process.

The first lens examines how far the tools have evolved from building assessment methods. The indicators that consider aspects of detailed building design (e.g. building materials, technologies, energy use levels) are quantified. While these indicators can be useful at later stages of urban design, they require information that is not readily available when building massing is being developed. Providing this information is speculative and, at best, just sets the desirable target. Also quantified are how many indicators cover each pillar of the TBL to make a more integrated and holistic sustainability assessment, especially in relation to social concerns. Finally, how many indicators consider the urban context and location, and how many measure aspects of the planning process (e.g. mechanisms of public participation) are determined. These are all important dimensions of the sustainable urban development planning process that are not usually found in building assessment methods (Curwell and Cooper, 1998; Ding, 2008).
The second lens examines to what extent the tools directly measure the design outcome. This is defined by the dimensions of urban form as proposed by Dempsey et al. (2008) in the context of sustainable urban development (i.e. land use, density, mobility infrastructure, street layout and building type, as well as accessibility, which is identified as a unifying measure). In the design process, it is important that the indicators make the consequences of design actions directly observable and understood by the stakeholders to facilitate the interaction and iteration processes. In contrast, we quantify to what extent the tools include indicators that measure externalities of the urban design process. These can be market conditions such as affordability of the housing stock or aspects of individual lifestyle (e.g. levels of home working). Furthermore, we quantify the indicators that can only be measured at a different stage of the development process, with data collected prior to the design stage for baseline assessment or after the design stage for monitoring progress (e.g. crime rates, population profile, resident satisfaction).

\subsection{Tool output}

The final stage of analysis looks at the tools' output and what strategies they offer to tackle the serious difficulties in assessing the results of indicators, as raised by Briassoulis (2001). 


\begin{tabular}{|c|c|c|c|}
\hline Project & Origin & Period & Website/database \\
\hline Bequest & EU & 1998-2001 & http://vp.salford.ac.uk/bequest/bequestWebs/bqtoolkit/index2.htm \\
\hline Crisp & EU & $2000-2003$ & http://crisp.cstb.fr/ \\
\hline $\mathrm{HQE}^{2} \mathrm{R}$ & EU & 2001-2004 & http://hqe2r.cstb.fr/default.asp \\
\hline PETUS & EU & $2003-2006$ & http://www.petus.eu.com/ \\
\hline SustainabilityA-Test & EU & 2004-2006 & http://www.sustainabilitya-test.net/ \\
\hline SUE-MoT & UK & 2003-2009 & http://www.sue-mot.org/ \\
\hline
\end{tabular}

Table 1. Overview of research projects reviewing sustainable urban development evaluation tools

How the various targets are set in benchmark values. According to Briassoulis, this is a difficult - if not impossible - task. Having pre-set values is satisfactory if the levels are adequate for the local geographic or policy context, or to obtain results that are comparable with reference cases. According to other authors, customisation of these values is a prerequisite for the evaluation process (Hunt et al., 2008; Mitchell, 1996; Pope et al., 2004).

- How the various disaggregate indicators are summarised using weights, if the synergies between indicators are accounted for and how transparent this aggregation process remains (Becker, 2004; Hacking and Guthrie, 2008). While a final score might be interesting for certification of a final proposal, it is not useful during the design stage because the complexity of the urban design process does not lend itself for optimisation strategies (Munda, 2006). It is more important to assess the disaggregate impacts and identify synergies in order to propose alternatives.

The visual feedback provided by the tools is also important because formal measurement and informal interpretation go hand in hand (Carmona, 2003). Effective graphic communication of the results allows the involvement of a wider group of stakeholders and can provide a clearer overview of the strengths and weaknesses of a proposal, thus operationalising the evaluation process (Becker, 2004).

\section{Selecting a relevant set of sustainable urban development evaluation tools}

Having established an analytical framework for the review of sustainable urban development evaluation tools, the next step is to identify and select a group of relevant tools that can support the assessment of alternative master plans, or detail urban design options, during the design phase of an urban area renewal and development process. The best way to produce a design outcome that moves closer to sustainability goals is if these support tools are used from the earliest stage of planning, namely from the development visioning stage (Hunt et al., 2008).

\subsection{Sources of information}

The tool selection process is based on a survey of various sources, including previous sustainable urban development evaluation tool reviews, academic research projects and the internet.

Previous reviews have analysed sets of sustainable urban development tools for urban area development (Hunt et al., 2008; Kapelan et al., 2005; Karol and Brunner, 2009). Hunt et al. (2008) reviewed tools that have been applied over the years in the development of Birmingham Eastside, in the UK, concluding on their usefulness but identifying requirements for their wider dissemination. Karol and Brunner (2009) reviewed tools that are relevant to support the development of multihousing subdivision projects in the specific context of Western Australia, focusing on their content, relating themes to more general sustainability concepts and the objective sustainability targets.

The results of academic research projects are another rich source of information. Several projects have compiled the state-of-the-art in sustainable urban development evaluation tools, identifying hundreds of different tools through extensive literature reviews, stakeholder workshops and consultations (Bourdeau and Nibel, 2004; Cremasco, 2007; Deakin et al., 2002; Jones and Patterson, 2007; Levett-Therivel, 2004; Walton et al., 2005). In the process, they have further developed the understanding of sustainable urban development evaluation by establishing classification parameters for different phases of the urban development process, different temporal and spatial scales of intervention, all sustainability dimensions and a wide range of stakeholders. Table 1 gives a brief overview of relevant projects.

Of particular relevance to this review were the databases, reports and articles resulting from projects that review integrated evaluation methods applicable at the urban scale (Blum and Grant, 2006; Jensen and Elle, 2007; LevettTherivel, 2004; McCreadie and BRE, 2004) and the works that describe sustainable urban development evaluation 
Urban Design and Planning

Volume 166 Issue DP6
Tools for evaluating the

sustainability of urban design:

a review

Gil and Duarte

\begin{tabular}{|c|c|c|c|c|c|}
\hline Name & Country & Gov & Ind & Aca & NGO \\
\hline Action Towards Local Sustainability (Atlas) & EU & 5 & 1 & & \\
\hline BRE Sustainability Checklist & UK & & 1 & & \\
\hline Breeam Communities* & UK & & 1 & & \\
\hline Citycad & UK & & 1 & & \\
\hline CommunityViz & US & & 1 & & 1 \\
\hline Dashboard of Sustainability & CAN & & & & 1 \\
\hline Duurzaamheids Profiel van een Locatie (DPL) & $\mathrm{NL}$ & & 2 & & \\
\hline EcoCity & $A T, D E, N L$ & 1 & & 2 & \\
\hline Ecological Footprint & US & & & 1 & \\
\hline Ecosistema urbano & IT & & & 1 & \\
\hline Environmental impact assessment (EIA) & EU & 1 & & & \\
\hline European common indicators $(\mathrm{ECl})^{\star}$ & IT, EU & 1 & 1 & & 1 \\
\hline $\mathrm{HQE}^{2} \mathrm{R}$ (ISDIS systems and INDI model)* & $F R, E U$ & & & 10 & \\
\hline Index & US & & 1 & & \\
\hline Land use evolution and impact assessment model (LEAM) & US & & & 1 & \\
\hline Leed for neighbourhood development (Leed-ND) & US & 2 & 1 & & \\
\hline Multi-criteria assessment tool (NAIADE) & ES & & 1 & & \\
\hline OnePlanetLiving & UK & & & & 2 \\
\hline PERS & UK & 1 & 1 & & \\
\hline Place3s & US & 3 & & & \\
\hline Placecheck & UK & & & & 1 \\
\hline Polestar & US & & & & 1 \\
\hline Propolis* & EU & & 6 & 2 & \\
\hline Quality of life indicators* & UK & 1 & & & \\
\hline $\begin{array}{l}\text { South East of England Development Agency (Seeda) sustainability } \\
\text { checklist }\end{array}$ & UK & 1 & 1 & & 1 \\
\hline $\begin{array}{l}\text { Sistema de indicadores y condicionantes para ciudades grandes y } \\
\text { medianas (SIC) }\end{array}$ & ES & 1 & 1 & & \\
\hline Shaping Neighbourhoods (SN) & UK & & & 1 & \\
\hline Social impact assessment (SIA) & EU & & & 1 & \\
\hline Solutions & UK & & & 6 & \\
\hline Spaceshaper & UK & & 1 & & \\
\hline Spartacus & EU & & 4 & 1 & \\
\hline Spear & UK & & 1 & & \\
\hline $\begin{array}{l}\text { Sustainable urban landscapes (SUL): the site design manual for } B C \\
\text { communities }\end{array}$ & CA & & & 1 & \\
\hline Toolbox for regional policy analysis & US & 3 & & & \\
\hline Urbanizing suburbia* & UK & & & 1 & \\
\hline
\end{tabular}

frameworks incorporating those methods (Bentivegna et al., 2002; Deakin et al., 2001, 2002; Jones and Patterson, 2007).

A final source of information on sustainable urban development evaluation tools was the internet and references in professional planning resources; these cover more recent tools not necessarily from an academic origin.

\subsection{Tool identification and selection}

The first task was to identify a list of candidates for review from the enormous quantity of sustainable urban development evaluation tools available. This meant selecting those tools that can be applied at the neighbourhood scale and offer integrated assessment of all sustainability dimensions, leaving out those targeted specifically at the building, building components, whole 
Urban Design and Planning

Volume 166 Issue DP6
Tools for evaluating the

sustainability of urban design:

a review

Gil and Duarte city or regional scales, or that focus on specific issues like energy or transport. Also excluded were the tools for which no other information could be found beyond the initial database entry or report reference.

Table 2 presents the list of the 35 tools identified, including the tool's name, its country of origin and the number of different organisations involved in its development (i.e. government agencies (Gov), academic institutions (Aca), industry members (Ind) and non-governmental organisations (NGO)). These tools were reviewed to select those that can be used for ex ante evaluation of projects to compare design alternatives and have the form of a system of indicators. Particular attention was given to tools endorsed by national or local government.

Some candidates were excluded because they have been superseded by more recent versions; namely, Spartacus and Propolis, which have been integrated into Solutions. Other candidates were excluded because they are evaluation frameworks that integrate several tools but lack specific methods (Brandon and Lombardi, 2010; Cole, 2005) and are more suitable for the final stage of design certification (namely EIA, SIA and Breeam Communities). In the case of Breeam Communities (BRE Global, 2009), several indicators use data from the development process instead of the design output (such as the presentation of impact assessment reports and emails between the planning team), these being more suited for a retrospective analysis (Brandon and Lombardi, 2010). In fact, the Breeam Communities framework recommends the use of other practical assessment methods, some of which are covered in this article. This first review resulted in a shortlist of 11 tools selected for detailed assessment; these are shown in italic in Table 2.

\subsection{Summary of the selected tools}

- Citycad (http://www.holisticcity.co.uk/) is a design support software program developed in the UK by Holistic City and targeted at urban design professionals. It offers a parametric model for urban master plans within a cad environment that provides real-time feedback on a variety of sustainability and quality of life indicators, while changes are made to the design.

- Duurzaamheids Profiel van een Locatie (DPL) (http://www. ivam.uva.nl/index.php?id=560) is a sustainable neighbourhood assessment software tool from the Netherlands developed by IVAM that can be used at various stages of the development process. The software has been used by more than 35 municipalities in the Netherlands and is endorsed by the government in the sustainable procurement of urban development projects.

- EcoCity Book 2 (Gaffron et al., 2008) is a guidance document resulting from the EU research project EcoCity
'Urban development towards appropriate structures for sustainable transport' (2002-2005). It developed an EcoCity vision based on existing guidance and principles of sustainable urban development. This book provides guidance on the sustainable urban planning process and includes an assessment method based on sustainability indicators.

- Index (http://www.crit.com/) is an integrated decision support tool developed by Criterion Planners in the USA and based on a GIS platform. It supports all stages of the urban development process from initial assessment to monitoring of the conditions, and has a range of different modules for this purpose including some simulation modules. Its set of indicators includes several from the Leed-ND system.

Leadership in energy and environmental design neighbourhood development (Leed-ND) (http://www.usgbc.org/ DisplayPage.aspx?CMSPageID $=148)$ is a rating system developed by the US Green Building Council (USGBC) in collaboration with the Congress for the New Urbanism (CNU) and the Natural Resources Defence Council (NRDC) in the USA. It is the result of a consultation process concluded in 2009 that resulted in the publication of the rating system specification and a project checklist. The certification process has several stages and is carried out by the USGBC through accredited professionals.

- South East of England Development Agency (Seeda) sustainability checklist (http://southeast.sustainabilitychecklist.co.uk/) was an on-line decision support tool developed by Seeda and the Building Research Establishment (BRE) in the UK. It offered guidance for the design of new urban development projects in light of current policy and best practice. The project was subsequently adapted to several other regions in the UK, but is no longer supported since the closure of all regional development agencies in March 2012.

- Sistema de Indicadores y Condicionantes para ciudades grandes y medianas (SIC) (MMAMRM and BCN, 2010) is a system of indicators for measuring the sustainability of cities. Officially approved in 2010 as the standard for Spanish cities, it was developed by a workgroup of municipalities of the Local Agenda 21 programme under technical supervision of the Agencia de Ecologia de Barcelona.

- Shaping Neighbourhoods (SN) (Barton et al., 2010) is a book by academics from the University of the West of England in the UK, providing guidance in the design of sustainable, healthy neighbourhoods. It offers theoretical principles, practical guidelines on urban form and a series of checklists for different stakeholders and different stages of the development process.

- Sustainability of land use and transport in outer neighbourhoods (Solutions) (http://www.suburbansolutions.ac.uk/) 
Urban Design and Planning

Volume 166 Issue DP6
Tools for evaluating the

sustainability of urban design:

a review

Gil and Duarte was a UK research project (2004-2008) to develop and assess different urban design and development scenarios for the future in terms of their sustainability. Within this project, an evaluation framework was developed based on sustainability indicators for local (Barton et al., 2009) and regional scales (Mitchell et al., 2005).

- Sustainable project appraisal routine (Spear) (http://www arup.com/Projects/spear.aspx) is an integrated decision support software developed by Arup/Oasys in the UK in 2000. Designed to use in all types and scales of projects, it has been used in master planning at Arup (McGregor and Roberts, 2003). It is known for its circular diagram that summarises the results.

- Sustainable urban landscapes (SUL): the site design manual for BC communities (http://www.jtc.sala.ubc.ca/projects/ DesignManual.html) is a design guidance tool produced at the University of British Columbia in Canada with the support of regional and national government agencies. It offers an introduction to the assessment method using several case studies, as well as design codes and a sustainability checklist.

\section{Review of selected tools}

This section reviews the selected sustainable urban development evaluation tools based on the analytical framework defined in Section 3. For each aspect of the framework, the main findings (or trend if it exists) are highlighted, along with the details for each individual tool summarised in tables and charts.

One initial consideration is about the extent to which the selected sustainable urban development evaluation tools are explicit about background references. These references can originate in theoretical research, empirical research, policy and guidance documents or industry best practice and standards, and they should inform all aspects of tool development. However, some tools do not have a references section or footnotes making those links (Citycad, Index, Leed-ND), in contrast to DPL and Seeda, which have comprehensive references to local policy documents, or the tools that involved academic institutions. This omission leads to a lack of transparency on the reasons behind certain features, settings or selections of indicators.

\subsection{Format of the tools}

The format characteristics of the selected sustainable urban development evaluation tools are summarised in Table 3, including tool type, product type, software platform (with any auxiliary tools in brackets), input data used for measurement and customisation options.

The first characteristic highlighted is the type of tool. The selected tools cover the four types defined in Section 3.1 (design guides, calculation tools, assessment tools and rating systems). However, only one tool is a rating system, which seems to confirm that the aggregation of measurements into a single score is not an essential feature for design support. The differences between calculation and assessment tools become clearer in the other stages of this review, in particular the reason why Index is considered a calculation tool.

The type has implications on the other characteristics of the tool. Design guides are available in the form of a book or report without a supporting software platform and offer paper

\begin{tabular}{|c|c|c|c|c|c|}
\hline Tool & Type & Product & Platform & Input data & Customisation \\
\hline Citycad & Calculation & Commercial software & Cad & Design & $\begin{array}{l}\text { Configuration of } \\
\text { settings }\end{array}$ \\
\hline DPL & Assessment & Commercial software & Spreadsheet & Design data & Alternative calculation \\
\hline EcoCity & Guide & Free report & Checklist & Result & - \\
\hline Index & Calculation & Commercial software & GIS & Design & Selection of indicators \\
\hline Leed-ND & Rating & $\begin{array}{l}\text { Commercial service, } \\
\text { free guide }\end{array}$ & Spreadsheet, (GIS) & Result & Reserved credits \\
\hline Seeda & Assessment & Free software & Website & Result & - \\
\hline SIC & Assessment & Free report & (GIS, other) & (Design) & - \\
\hline SN & Guide & Book & Checklist & Result & - \\
\hline Solutions & Assessment & Free report & (Other) & - & - \\
\hline Spear & Assessment & Commercial software & Spreadsheet & Result & $\begin{array}{l}\text { Selection and custom } \\
\text { indicators }\end{array}$ \\
\hline SUL & Guide & Free report & Checklist & Result & - \\
\hline
\end{tabular}

Table 3. Summary of the format of the selected sustainable urban development evaluation tools 

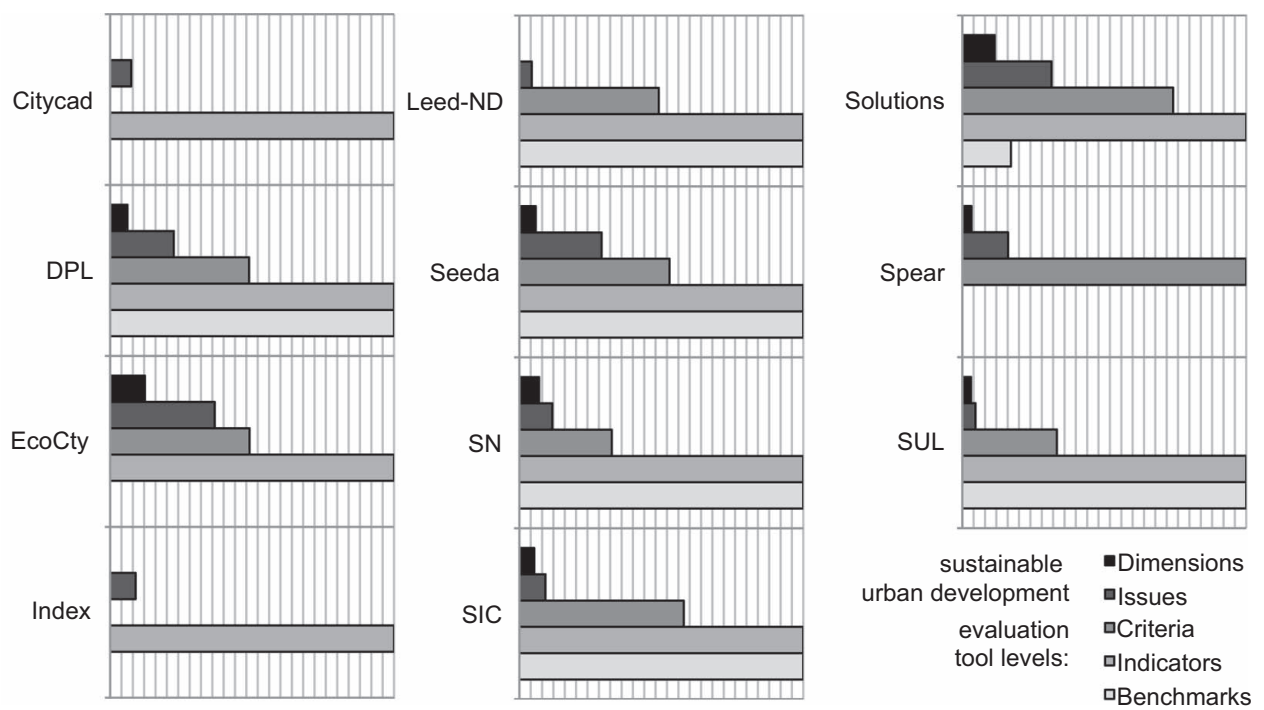

Figure 2. Configuration of the selected sustainable urban development evaluation tools, based on the general structure defined in the analytical framework

checklists to facilitate assessment. Some assessment tools are only available to the general public in the form of a report, although they mention auxiliary software that is used in the assessment process. The software platforms are mostly commercial, with the exception of the Seeda website and the Leed-ND checklist. They come in two types - spreadsheets or design platforms such as cad and GIS.

The type of input data required for measurement depends on the software platform, with consequences for ease of data entry and maintenance. Design platforms store the design directly, facilitating the measurement, calculation and update of alternative design options, rendering the evaluation process more interactive and iterative. Spreadsheets are normally used as digital checklists that store the result of each indicator, previously calculated by other means. The only exception is DPL, which takes design measurements and data as input and calculates the indicators automatically.

Finally, the customisation possibilities are very much dependent on all the previous characteristics. Most paper or digital checklists offer limited possibilities for customising the system of indicators. The software tools are eventually more flexible: Leed-ND has four reserved credits that can be defined to accommodate regional characteristics, Spear accepts the replacement of up to $10 \%$ of its indicators, DPL offers alternative calculations for some indicators based on different input data and Index offers the possibility of freely combining the indicators into a custom system of indicators specific to the project.

\subsection{Configuration of the tools}

The selected tools are all based on collections of sustainable urban development indicators grouped under hierarchical levels. However, the terms used to describe each level vary between tools and even the term 'indicator' is not used consistently, being explicitly defined only in EcoCity. To review the selected tools, they were conformed to the general structure of Figure 1 by matching the tools' levels to the proposed levels based on their characteristics and role in the evaluation process. Figure 2 presents the configuration of each of the selected sustainable urban development evaluation tools based on the number of elements in each level. A look at the group of charts in Figure 2 reveals that most tools do not present a complete sustainable urban development evaluation hierarchy: they do not cover the full range of levels, they have gaps or the levels are not clearly separated.

At the top level, only one tool is explicitly based on the TBL (DPL), while other tools adapt the TBL by separating the environmental dimension into 'environment' and 'resources' (Solutions, Spear) or by adding a 'transport' dimension (SUL). Several tools start from a set of dimensions that is specific to the urban development context (EcoCity, Seeda, SIC, SN), more akin to the 'issues' level, making them less compatible with general definitions and policy on sustainable development. However, three tools do not address any high-level concepts of sustainability (Citycad, Index and Leed-ND).

Most tools include all the other levels down to the definition of targets in the form of benchmark values or design patterns 
Urban Design and Planning

Volume 166 Issue DP6
Tools for evaluating the

sustainability of urban design:

a review

Gil and Duarte
(SUL). Spear does not specify design indicators or benchmark values and only defines what should be evaluated and why, leaving the system open for application in many different contexts.

Citycad and Index consist of collections of design indicators associated with urban issues without a complete hierarchical organisation. These gaps in the sustainable urban development evaluation structure force conceptual jumps in the construction and interpretation of a system of indicators, making it difficult to link the specific measurements of urban form to a general understanding of progress towards sustainability.

\subsection{What are the tools measuring?}

Let us now look at the content of the tools' indicators to understand what they are measuring and to what extent it is relevant to the early design stages of urban area development. This is done using two 'lenses' - one to view to what extent the tools measure the sustainability of an urban area and the other to view to what extent they measure the design outcome.

The first lens is illustrated in Figures 3 and 4. Figure 3 shows the representativeness of each pillar of the TBL among the indicators of a tool. Since few tools start from the TBL, this measure was inferred from the content and phrasing of each indicator. All the tools cover the three pillars of sustainability, except for LeedND, which lacks any indicator explicitly addressing the economic dimension. On the other hand, the social dimension is well represented in every tool, demonstrating the importance that social aspects have in urban area development.

Figure 4 shows the share of indicators that address building design details, the urban context and the planning process. Most tools include $25 \%$ or more indicators addressing building design issues, showing that they have directly evolved from or

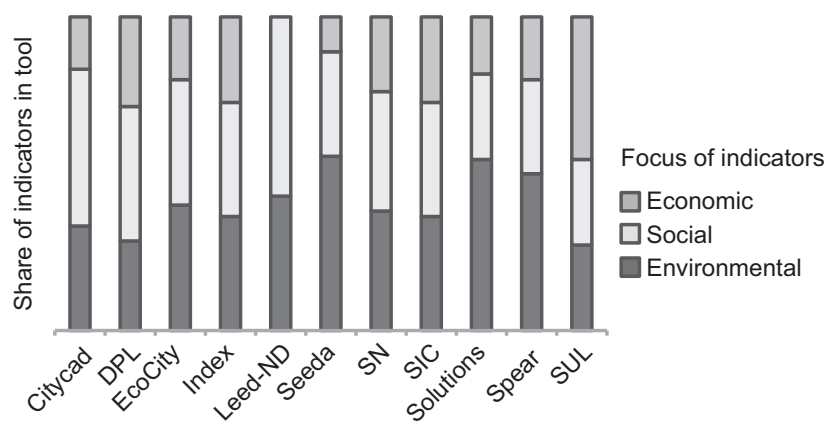

Figure 3. Representativeness of the three pillars of sustainability in the selected sustainable urban development evaluation tools; the bars indicate how many times each pillar is addressed by an indicator

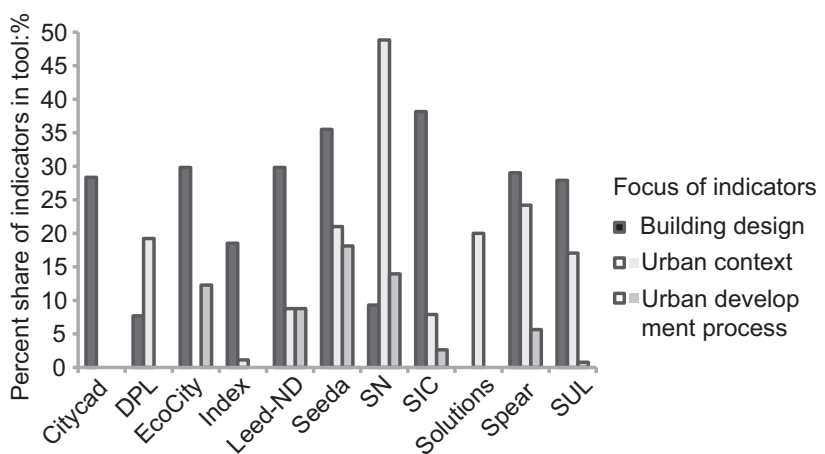

Figure 4. Percent share of indicators that demonstrate how far the tools have evolved from building energy assessment tools to urban design assessment tools. Less building design related indicators and more urban context/development process indicators demonstrates a tool oriented towards urban design evaluation

incorporate building evaluation frameworks (Leed-ND, Seeda, SIC, Spear). Only the Solutions tool has no indicator of building design, demonstrating its focus on the planning scale. When it comes to urban context, such as the immediate surroundings of an urban area or its location within the city, Citycad and EcoCity fail to address it. As input, Citycad takes the design of the master plan and no other contextual information. Along with DPL, Index and Solutions, Citycad also lacks any indicator specifically about the planning process, in contrast to the tools that involved government institutions or are strongly based on local policy (EcoCity, Leed-ND, Seeda, and SN). However, one could argue that all the sustainable urban development evaluation tools reviewed support an interactive and communicative planning process and their use should provide implicit

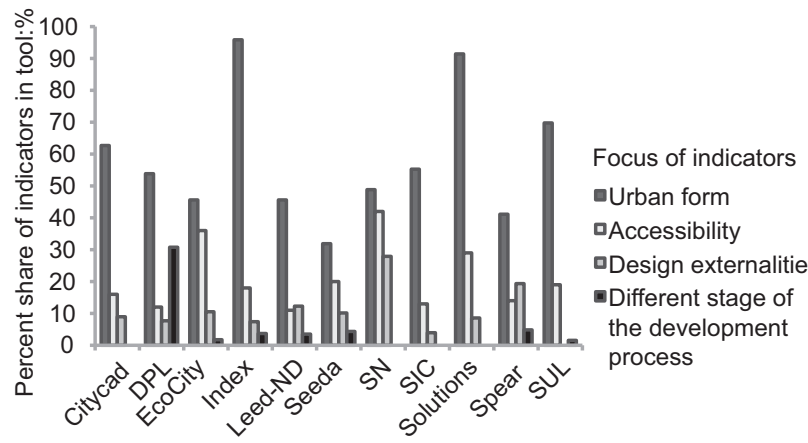

Figure 5. Percent share of indicators that demonstrate to what extent the tools directly measure aspects of urban form. More urban form/accessibility indicators and less indicators measuring design externalities or different stages of the development process demonstrates a tool with a high potential of interaction with the design team 
demonstration of that concern by the urban development team. Index in particular provides an extensive description of how the tool integrates into the various stages of the planning process.

The second lens is illustrated in Figure 5. This shows the extent to which the indicators are measuring the urban design outcome, supporting an iterative design process where stakeholders are capable of assessing different design alternatives and designers more readily understand the implications of their actions. In general, the tools considered for review have more than $40 \%$ of indicators measuring urban form, especially Citycad, Index, Solutions and SUL, with the exception of Seeda. Combining these urban form indicators with those assessing aspects of the sustainable planning process, all tools display more than $50 \%$ of relevant indicators. This was one of the last selection criteria applied to the list of tools in Table 2, where those with an asterisk show less than $33 \%$ of relevant indicators.

In contrast, Figure 5 also shows the indicators that measure externalities of the urban design process and ones that would only be applicable for assessing existing conditions or afterwards for monitoring the development progress. Only SUL has no indicator addressing design externalities because its focus is on design principles and design codes. SN has the most, such as 'sense of community' and 'healthy life styles', which cannot be measured from the urban design output alone. When it comes to addressing different stages of the planning process, DPL has $30 \%$ of its indicators requiring survey data of the existing population, employment, crime and pollution, or questionnaires of residents that would only be obtained in the monitoring stage of urban development.

\subsection{Output of the evaluation results}

The final stage of this analysis is to consider the output of the sustainable urban development evaluation, looking at the multi-criteria features and the graphical output, as summarised in Table 4.

All the evaluation tools reviewed are based on disaggregate systems of indicators and one should expect them to provide multi-criteria features for dealing with weighting, aggregation, synergies and benchmarks of the indicators. Regarding weights and aggregation, an essential aspect of MCA, five tools feature them explicitly, either hardcoded in the model (Leed-ND, Seeda, Solutions) or customisable for each project (DPL, Index). The custom option is preferable because determining the weights is a task of the evaluation process that is eventually more important than the results in promoting discussion between stakeholders and keeping the aggregation transparent (Hacking and Guthrie, 2008). Where the tools lack such features, one should use an external MCA method.

Another important feature that should be addressed in systems of indicators is the synergies or interrelations between indicators. One approach is to build these relations into the evaluation models, making certain indicators depend on the results of others, or duplicating indicators under different issues to propagate their impact (DPL, Leed-ND, and Spear). Another approach is to explain the issue without attempting to resolve it. Design guides make the relations explicit in tables and diagrams mapping the overlaps between different levels of the system's hierarchy (EcoCity, SN, Solutions) or crossreferencing related assessment criteria, indicating their link to different issues and other criteria (Leed-ND, SN, SUL).

Another approach is to use indicators that involve multiple aspects of urban form (e.g. non-residential density combines land use and density). Accessibility indicators are particularly integrative in relating urban layout, mobility infrastructure, density and land use (Dempsey et al., 2008). This means that a

\begin{tabular}{llllll}
\hline Tool & Weights & Aggregation & Synergies & Benchmarks & Standard output \\
\hline Citycad & - & - & - & - & Map, table, chart, report \\
DPL & Custom & Issue & Built-in & Fixed & Chart \\
EcoCity & - & - & Diagrams & Fixed & Chart \\
Index & Custom & Full & - & Custom & Map, table, chart \\
Leed-ND & Fixed & Full & Built-in & Fixed & Label \\
Seeda & Fixed & Issue & - & Fixed & Chart, table \\
SIC & - & - & - & Fixed & - \\
SN & - & - & Diagrams & Fixed & - Chart, table \\
Solutions & Fixed & Criteria & Diagrams & Fixed & Chart \\
Spear & - & Issue & Built-in & - & -
\end{tabular}

Table 4. Summary of the output characteristics of the selected sustainable urban development evaluation tools 
Urban Design and Planning

Volume 166 Issue DP6
Tools for evaluating the

sustainability of urban design:

a review

Gil and Duarte change to any of the urban form dimensions involved will have an impact on the measurement results. Accessibility indicators are present in every tool (see Figure 5) and, in the case of EcoCity and $\mathrm{SN}$, represent almost all urban form indicators.

Regarding benchmark values, most tools offer fixed sets of levels to test the indicators against. Index is the only tool that offers an open platform where these benchmarks are defined early on, as part of the planning evaluation process.

Finally, let us briefly consider the graphical output offered by the selected tools. Most tools feature a standard chart summarising the result, acknowledging the importance of communicating the results clearly, succinctly and to a wide audience. Because of the complexity of the subject matter and in an attempt to avoid masking the multi-criteria nature of the evaluation process, the preferred chart is the multi-level pie chart for which Spear became known (Carmona and Sieh, 2008), with small variations between the different tools. The tools based on graphical software platforms (Citycad and Index) feature the possibility of mapping the results in a two- or three-dimensional representation of the urban area, offering spatial disaggregation of several indicators. This is essential information for urban design teams because it reports directly on the design outcome and increases the level of interaction of the tools.

\section{Discussion}

This section of the article presents a series of general recommendations regarding the development of sustainable urban development evaluation tools for urban design practice, based on the findings of the analysis of tools and the recommendations of planning evaluation theory.

Starting from the proposition that there is a gap between theory and practice (Alexander, 1997; Khakee, 2003), this review seems to confirm it to some extent. Looking at Table 2 and focusing on the institutions involved in the development of the different tools, there were only two (closely related) cases in which there was direct collaboration between industry and academia or between government and academia. Academic initiatives are independent and government, industry and NGOs form partnerships. Of course, there are references to policy and academic research in some of the tools reviewed, and some of the research projects listed in Table 1 included consultation with different stakeholder groups. This influence should be reinforced in future generations of sustainable urban development evaluation tools to achieve greater conceptual robustness. A four-goal strategy is proposed - collaboration, compatibility, customisation and combination.

To start, there should be collaboration between different types of institutions because the theory/practice gap also seems to be one of direct involvement in each other's activities. The aim of collaboration is not necessarily to remove this theory/practice gap by aligning individual practices, but to create bridges for knowledge transfer and to offer opportunities for crossvalidation of knowledge and practices in real contexts (Alexander, 2006). Such initiatives include the UrbanBuzz programme in the UK (http://www.urbanbuzz.org/).

The aim of compatibility is to develop accepted sustainable urban development definitions into a standard theoretical framework of sustainable urban development principles and issues, which would offer clarity and legitimacy to the evaluation tools that adopt them (Carmona and Sieh, 2008; George, 2001; Oliveira and Pinho, 2010; Walton et al., 2005). These high-level standards would be used for top-down structuring of the systems of indicators, as shown in Figure 1, linking the sustainability dimensions to the design indicators and benchmark values. The results from these systems would then be more compatible and comparable (Archibugi, 2006). With such a starting point, one might avoid the pitfalls of calculation tools that offer a long list of indicators driven by the available data and what can be calculated with given the software platform, resulting in data-rich and information-poor evaluations (Carmona and Sieh, 2008).

Obviously, complete standardisation is not possible, nor desirable (Carmona, 2003), and should be complemented with customisation at the detail level of indicators and benchmark values to address the complexities and specificities of urban design projects and of the local context (Mitchell, 1996). Otherwise, sustainable urban development evaluation tools can include design principles that are not universally accepted, require data that are not available locally or include indicators and benchmark values that are not relevant to the specific geographic, policy or project context.

It is unlikely that compatibility and customisation will lead to convergence into a single tool. Therefore, the combination of tools and methods is advisable. One should consider the use of different tools by different stakeholders or at different phases of the development process (Levett-Therivel, 2004), as long as they are compatible. If the tools start from a common standard theoretical framework it becomes easier to choose complementary methods, such as indicator systems, MCA, EIA or SEA, as recommended in integrated evaluation frameworks (Archibugi, 2006). At another level, combination should enable the pairing of different tool formats, namely the design guide and the calculation software (see Table 3). The former offers sound theory and a universally accessible format, while the latter offers operational and interactive qualities for design support with effective output for communication. As Alexander (2006) concludes, the solution is to blend both extremes in a process that integrates sound knowledge and effective communication. 
Urban Design and Planning

Volume 166 Issue DP6
Tools for evaluating the

sustainability of urban design:

a review

Gil and Duarte

\section{Conclusions}

This paper has reviewed the state-of-the-art in sustainable urban development evaluation tools that are suitable for application at the early stages of urban area design and development. A set of 11 tools has been identified based on systems of indicators, confirming the preference for this evaluation method for application in practice at the scale of the urban area. The review then applied an analytical framework to the selected tools, following recommendations of planning evaluation theory and requirements of practice. This covered aspects of their format, structure, content and output, and revealed a very diverse picture with some general trends but no single tool standing out as the 'right one' to use especially in terms of a sustainability framework structure. Each tool shows strengths and weaknesses, leaving urban design teams interested in using an evaluation tool in their project with the option of adopting a tool with content most compatible with the local geographic or policy context or a tool that better supports the design process with the most convenient input, platform and output options.

To conclude, this review has explored the gap between theory and practice in the development of sustainable urban development evaluation tools, where collaboration between academic and other institutions is most rare. A strategy for the development of future tools is proposed, based around the four goals of collaboration, compatibility, customisation and combination. This strategy should facilitate the development of tools that are more robust and compatible in terms of sustainability principles, but also flexible in adapting to local contexts. These could form a collection of different but compatible tools and methods that can be more readily combined to offer comprehensive planning evaluation frameworks, catering for the different expertise of the various stakeholders and the various stages of the sustainable urban development process.

\section{Acknowledgements}

This research was part of the 'City Induction' project hosted at the Technical University of Lisbon and funded by Fundação para a Ciência e Tecnologia (FCT), Portugal, through grant PTDC/AUR/64384/2006. Jorge Gil is conducting his research at the Department of Urbanism of Delft University of Technology, under the supervision of Prof. Vincent Nadin and Dr Stephen Read, funded by FCT with grant SFRH/BD/46709/2008.

\section{REFERENCES}

AIRI (Ambiente Italia Research Institute) (2003) European Common Indicators: Towards a Local Sustainability Profile. European Commission, Milan, Italy.

Alexander ER (1997) A mile or a millimeter? Measuring the 'planning theory-practice gap'. Environment and Planning B: Planning and Design 24(1): 3-6.

Alexander ER (2000) Rationality revisited: planning paradigms in a post-postmodernist perspective. Journal of Planning Education and Research 19(3): 242-256.

Alexander ER (2006) Problems and prospects: dilemmas in evaluation and directions for the future. In Evaluation in Planning: Evolution and Prospects (Alexander ER (ed.)). Ashgate, Aldershot, UK, pp. 267-276.

Archibugi F (2006) Pitfalls in planning and plan-evaluation. In Evaluation in Planning: Evolution and Prospects (Alexander ER (ed.)). Ashgate, Aldershot, UK, pp. 73-83.

Barton H, Rice L, Grant M, Horswell M and Breeze M (2009) Solutions - London Local Case Study - Final Report. University of the West of England, Bristol, UK.

Barton H, Grant M and Guise R (2010) Shaping Neighbourhoods: A Guide for Health, Sustainability and Vitality. Spon Press, London, UK.

Becker J (2004) Making sustainable development evaluations work. Sustainable Development 12(4): 200-211.

Bentivegna V, Curwell S, Deakin M et al. (2002) A vision and methodology for integrated sustainable urban development: BEQUEST. Building Research and Information 30(2): 83-94.

BioRegional (2009) BedZED Seven Years On - The Impact of the UK's Best Known Eco-village and its Residents. BioRegional, Wallington, UK.

Blum A and Grant M (2006) Sustainable neighbourhoods: assessment tools for renovation and development. Journal of International Research Publications: Ecology and Safety 1: $35-52$.

Bourdeau L and Nibel S (2004) CRISP: A European Thematic Network on Construction and City Related Sustainability Indicators. European Commission, Brussels, Belgium, EVK4-CT1999-20002.

Brandon P and Lombardi P (2010) Evaluating Sustainable Development in the Built Environment. Wiley, Chichester, UK.

BRE Global (Building Research Establishment Global) (2009) BREEAM Communities Technical Guidance Manual. BRE, Watford, UK.

Briassoulis H (2001) Sustainable development and its indicators: through a (planner's) glass darkly. Journal of Environmental Planning and Management 44(3): 409-427.

Carmona M (2003) An international perspective on measuring quality in planning. Built Environment 29(4): 281-287.

Carmona M and Sieh L (2008) Performance measurement in planning - towards a holistic view. Environment and Planning C: Government and Policy 26(2): 428-454.

Colantonio A (2008) Measuring Social Sustainability: Best Practice from Urban Renewal in the EU. European Investment Bank, Luxembourg, EIBURS Working Paper 2008/02.

Cole RJ (1999) Building environmental assessment methods: clarifying intentions. Building Research \& Information 27(4-5): 230-246.

Cole RJ (2005) Building environmental assessment methods: 
Urban Design and Planning

Volume 166 Issue DP6
Tools for evaluating the

sustainability of urban design:

a review

Gil and Duarte redefining intentions and roles. Building Research \& Information 33(5): 455-467.

Cooper I (1999) Which focus for building assessment methods environmental performance or sustainability? Building Research \& Information 27(4-5): 321-331.

Cremasco V (2007) Sustainability tools dedicated to urban infrastructure: the existing and the distinctiveness of PETUS. Indoor and Built Environment 16(3): 226-234.

Curwell S and Cooper I (1998) The implications of urban sustainability. Building Research \& Information 26(1): 17-28.

DCLG (Department for Communities and Local Government) (2005) Planning Policy Statement 1: Delivering Sustainable Development. DCLG, London, UK.

Deakin M, Curwell S and Lombardi P (2001) Bequest: the framework and directory of assessment methods. International Journal of Life Cycle Assessment 6(6): 373-383.

Deakin M, Huovila P, Rao S, Sunikka M and Vreeker R (2002) The assessment of sustainable urban development. Building Research \& Information 30(2): 95-108.

Defra (Department for Environment, Food and Rural Affairs) (2009) Sustainable development Indicators in your Pocket 2009 Edition. Defra, London, UK.

Dempsey N, Brown C, Raman S et al. (2008) Elements of urban form. In Dimensions of the Sustainable City (Jenks M and Jones C (eds)). Springer, Dordrecht, Netherlands, pp. 2151.

Ding KC (2008) Sustainable construction - the role of environmental assessment tools. Journal of Environmental Management 86(3): 451-464.

European Commission (1998) Sustainable Urban Development in the European Union: A Framework for Action. European Commission, Brussels, Belgium.

European Council (2007) Leipzig Charter. European Council, Brussels, Belgium.

Gaffron P, Huismans G and Skala F (eds) (2008) EcoCity Book 2. How to Make it Happen. Facultas, Vienna, Austria.

Gasparatos A, El-Haram M and Horner M (2009) The argument against a reductionist approach for measuring sustainable development performance and the need for methodological pluralism. Accounting Forum 33(3): 245-256.

George C (2001) Sustainability appraisal for sustainable development: integrating everything from jobs to climate change. Impact Assessment and Project Appraisal 19(2): 95-106.

Hacking T and Guthrie P (2008) A framework for clarifying the meaning of triple bottom-line, integrated, and sustainability assessment. Environmental Impact Assessment Review 28(2-3): 73-89.

Hunt D, Lombardi D, Rogers C and Jefferson I (2008) Application of sustainability indicators in decision-making processes for urban regeneration projects. Proceedings of the Institution of Civil Engineers - Engineering Sustainability 161(1): 77-91, http://dx.doi.org/10.1680/ensu.2008.161.1.77.

Jensen JO and Elle M (2007) Exploring the use of tools for urban sustainability in European cities. Indoor and Built Environment 16(3): 235-247.

Jones P and Patterson J (2007) The development of a practical evaluation tool for urban sustainability. Indoor and Built Environment 16(3): 255-272.

Kapelan Z, Savic DA and Walters GA (2005) Decision-support tools for sustainable urban development. Proceedings of the Institution of Civil Engineers - Engineering Sustainability 158(3): 135-142, http://dx.doi.org/10.1680/ ensu.2005.158.3.135.

Karol E and Brunner J (2009) Tools for measuring progress towards sustainable neighborhood environments. Sustainability 1(3): 612-627.

Khakee A (2003) The emerging gap between evaluation research and practice. Evaluation 9(3): 340-352.

Leitmann J (1999) Can city QOL indicators be objective and relevant? Towards a participatory tool for sustaining urban development. Local Environment 4(2): 169-180.

Levett-Therivel (2004) Sustainable Urban Environment Metrics, Models and Toolkits: Analysis of Sustainability/ Social tools. SUE-MoT Consortium, Oxford, UK.

Llewelyn-Davies and Alan Baxter \& Associates (2007) Urban Design Compendium: Urban Design Principles. English Partnerships and The Housing Corporation, London, UK.

McCreadie M and Building Research Establishment (BRE) (2004) Assessment of Sustainability Tools. SUE-MoT Consortium, Glasgow, UK.

McGregor A and Roberts C (2003) Using the SPeAR TM Assessment Tool in Sustainable Master Planning. Proceedings of US Green Building Conference, Pittsburgh, PA, USA. US Green Building Council, Pittsburgh, PA, USA.

Mitchell G (1996) Problems and fundamentals of sustainable development indicators. Sustainable Development 4(1): 1-11.

Mitchell G, Gawthorpe S and Namdeo A (2005) Evaluation Criteria for Solutions. EPSRC, Swindon, UK.

MMAMRM and BCN (Ministerio de Medio Ambiente, y Medio Rural y Marino and Agencia de Ecologia Urbana de Barcelona BCN) (2010) Sistema de Indicadores y Condicionantes para ciudades grandes y medianas. Ministerio de Medio Ambiente, Madrid, Spain.

Munda G (2006) Social multi-criteria evaluation for urban sustainability policies. Land Use Policy 23(1): 86-94.

Oliveira V and Pinho P (2010) Evaluation in urban planning: advances and prospects. Journal of Planning Literature 24(4): 343-361.

Pope J, Annandale D and Morrison-Saunders A (2004) Conceptualising sustainability assessment. Environmental Impact Assessment Review 24(6): 595-616.

RIBA (Royal Institute of British Architects) (2007) Outline Plan of Work 2007. RIBA, London, UK.

Rydin Y, Holman N, Hands V and Sommer F (2003) Incorporating sustainable development concerns into an urban regeneration project: how politics can defeat procedures. 
Journal of Environmental Planning and Management 46(4): 545-561.

Steinemann A (2001) Improving alternatives for environmental impact assessment. Environmental Impact Assessment Review 21(1): 3-21.

USC (United States Congress) (2010) Sustainable Urban Development Act of 2010, S.3229. USC, Washington, DC, USA.
VROM (Ministerie van Volkshuisvesting, Ruimtelijke Ordening en Milieubeheer) (2001) Making Space, Sharing Space - Fifth National Policy Document on Spatial Planning 2000/2020 Summary. VROM, The Hague, Netherlands.

Walton J, El-Haram M, Castillo N et al. (2005) Integrated assessment of urban sustainability. Proceedings of the Institution of Civil Engineers - Engineering Sustainability 158(2): 57-65, http:// dx.doi.org/10.1680/ensu.2005.158.2.57.

\section{WHAT DO YOU THINK?}

To discuss this paper, please email up to 500 words to the editor at journals@ice.org.uk. Your contribution will be forwarded to the author(s) for a reply and, if considered appropriate by the editorial panel, will be published as discussion in a future issue of the journal.

Proceedings journals rely entirely on contributions sent in by civil engineering professionals, academics and students. Papers should be 2000-5000 words long (briefing papers should be 1000-2000 words long), with adequate illustrations and references. You can submit your paper online via www.icevirtuallibrary.com/content/journals, where you will also find detailed author guidelines. 